\title{
XXIII. Notice of a new hydrated phosphate of lime
}

\section{John Percy M.D.}

To cite this article: John Percy M.D. (1845) XXIII. Notice of a new hydrated phosphate of lime , Philosophical Magazine Series 3, 26:172, 194-195, DOI: 10.1080/14786444508645102

To link to this article: http://dx.doi.org/10.1080/14786444508645102

册 Published online: 30 Apr 2009.

Submit your article to this journal 준

Џ Article views: 2

Q View related articles $₫$ 
XXIII. Notice of a new Hydrated Phosphate of Lime. By John Percy, M.D.*

$7 \mathrm{Y}$ a solution of common phosphate of soda, in a large quan1 tity of distilled water, add a solution of chloride of calcium till precipitation ceases. Immediately pass through the mixture, containing the phosphate of lime suspended, a current of carbonic acid gas, and continue this for about an hour; then filter immediately, and set aside the filtered liquor in a jar, the mouth of which is covered loosely with paper to keep out dust. In the course of a day or two, and sometimes in a much shorter time, crystals will appear on the surface, and will, when stirred with a rod, sink. After the lapse of several days a very sensible quantity of crystals may be collected. Transfer them to a filter, and wash with cold or tepid distilled water, and dry in a roarm place.

It occurs in the form of brilliant white scales, which, on examination with the microscope, are seen to consist of modified rhomboidal plates more or less broken and confused.

The salt melts with difficulty at an intense heat by the blowpipe on platinum foil. Heated to brightr redness in a platinum crucible, $3.21 \mathrm{grs}$. of salt lost 0.85 , and in a second experiment $3 \cdot 16 \mathrm{grs}$. lost $0.84 \mathrm{gr}$. I found that every trace of water was given off after exposure for 10 minutes or a quarter of an hour to a bright red heat.

Rose's plan was followed in determining the lime and phosphoric acid, which consists in dissolving in hydrochloric acid, then adding sulphuric acid, then alcohol, which precipitates the lime completely as sulphate.

I. 3.21 grs. of salt gave 2.51 of sulphate of lime.

II. 3.16 grs. $\quad \ldots \quad 2 \cdot 48$

Taking 28 as the equivalent of lime, and phosphoric acid as 72 , we have-

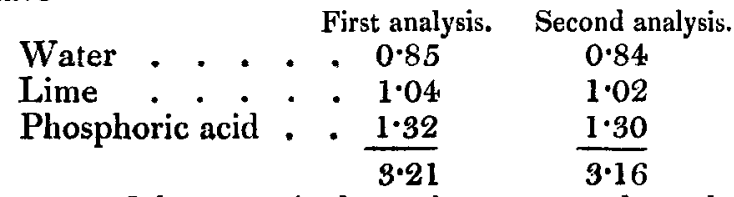

The oxygen of the water is three times as much as that of the base, and the salt agrees in composition with the formula $2 \mathrm{CaO}+\mathrm{PO}_{5}+6 \mathrm{HO}$.

'The rational formula will, doubtless, be $\mathrm{HO}, 2 \mathrm{CaO}, \mathrm{PO}_{5}$ $+5 \mathrm{HO}, 1$ equiv, of water being basic and 5 constitutional.

$2.40 \mathrm{grs}$. of this phosphate heated in the oil-bath at a temperature between $134^{\circ}$ and $148^{\circ}$ centig., lost $0.30 \mathrm{gr}$. in $1 \frac{1}{8}$

* Communicated by the Chemical Society; having been read November 18,1844 
hour, and no more than $0.31 \mathrm{gr}$. in $4 \frac{3}{4}$ hours, while at a red heat it would lose $0 \cdot 60$ gr. $0 \cdot 60-0 \cdot 31=0 \cdot 29$. We may therefore conclude that one-half of the water is expelled at the temperature above mentioned, giving another hydrate, $\mathrm{HO}$, $2 \mathrm{CaO}+\mathrm{PO}_{5}+2 \mathrm{HO}$.

XXIV. On a curious Change in the Composition of Bones taken from the Guano. By Robert Warington, Esq.*

MY friend Mr. Edwin Quekett, put into my hands a few $\mathbf{M}_{\text {days since, for the purpose of chemical examination, a }}$ curious crystalline substance taken from the guano, as inported from Ichaboe, and which he considered to have entirely replaced, and thus have assumed the form of, the original bony structure. The exterior surface, in many specimens, has portions of muscular fibre in a dry and pulverulent state closely in contact with the substance; small pieces of bony matter are also now and then found remaining, and in some cases the cylindrical part of the bone is perfectly modelled by this saline deposition or infiltration. The structure is highly crystalline and laminated, and in the cylindrical parts slightly radiating from the sides towards the centre; its colour is nearly white, with a slight shade of yellow, and generally very free from foreign matter, except at the parts where the enlarged or natural terminations of the bones may be supposed to have been, and in these places the substance is interspersed with small brown particles. It decrepitates in the flame of the spirit-lamp, assumes a gray colour, gives off ammoniacal vapour, and ultimately becomes perfectly white and opake; and by increasing the heat, by means of the blowpipe, it fuses and communicates a pinkish purple tinge to the flame, indicative of potash, and without any trace of yellow, showing its perfect freedom from soda salts. It was readily dissolved in hot distilled water, with the exception of the interspersed brown particles just alluded to; solution of nitrate of barytes threw down an abundant white granular precipitate insoluble in dilute nitric acid, consequently proving the presence, to a considerable extent, of sulphuric acid; solution of chloride of calcium occasioned no change, nor did the subsequent addition of ammonia cause any precipitation, so that the oxalic and phosphoric acids were both absent. Solution of oxalate of ammonia gave no indication of the presence of lime. By boiling, after adding solution of caustic potash, ammonia was evolved; nitrate of silver in a dilute solution, free nitric acid being present, caused no precipitation. The addition of tar-

* Communicated by the Chemical Society; having been read November 18, 1844. On Guano, seo p. 123 of the present volume. 